Research Paper

\title{
Mannose Binding Lectin and Macrophage Migration Inhibitory Factor Gene Polymorphisms in Turkish Children with Cardiomyopathy: No Association with MBL2 Codon 54 A/B Genotype, but an Association between MIF -173 CC Genotype
}

\author{
Nilgun Col-Araz ${ }^{1}$, Sibel Oguzkan-Balci ${ }^{\bowtie}$, Osman Baspinar ${ }^{3}$, Tugce Sever $^{2}$, Ayse Balat ${ }^{4}$, Sacide Pehlivan², \\ 1. University of Gaziantep, Faculty of Medicine, Department of Pediatrics, Gaziantep, Turkey. \\ 2. University of Gaziantep, Faculty of Medicine, Department of Medical Biology and Genetics, Gaziantep, Turkey. \\ 3. University of Gaziantep, Faculty of Medicine, Department of Pediatric Cardiology, Gaziantep, Turkey. \\ 4. University of Gaziantep, Faculty of Medicine, Department of Pediatric Nephrology, Gaziantep, Turkey.
}

$\triangle$ Corresponding author: Assos. Prof. Dr. Sibel Oguzkan Balci, University of Gaziantep, Faculty of Medicine, Department of Medical Biology and Genetics, 27310 Gaziantep, Turkey. E-mail: oguzkan@gantep.edu.tr Tel: +90 342 3606060, Fax: +90 342 3601617.

(c) Ivyspring International Publisher. This is an open-access article distributed under the terms of the Creative Commons License (http://creativecommons.org/ licenses/by-nc-nd/3.0/). Reproduction is permitted for personal, noncommercial use, provided that the article is in whole, unmodified, and properly cited.

Received: 2012.06.27; Accepted: 2012.08.19; Published: 2012.08.22

\begin{abstract}
Myocardial inflammation is one of the commonest mechanisms in cardiomyopathy (CMP). Mannose binding lectin (MBL) is a key molecule in innate immunity, while macrophage migration inhibitory factor (MIF) is a constitutive element of the host defenses. We investigated the possible association between polymorphisms of MBL2 and MIF genes and CMP in Turkish children. Twenty-children with CMP and 30 healthy controls were analyzed for codon $54 \mathrm{~A} / \mathrm{B}$ polymorphism in MBL, and - $173 \mathrm{G} / \mathrm{C}$ polymorphism in MIF genes by using PCR-RFLP methods. No significant difference was found between genotypes and alleles of MBL2 gene codon $54 \mathrm{~A} / \mathrm{B}$ polymorphism in patients and controls $(\mathrm{p}>0.05)$. However, serum uric acid levels was found higher in dilated CMP patients with AA genotype. Frequency of MIF - I73 CC genotype was significantly higher in patients $(p<0.05)$, and sodium levels were higher in patients with MIF - I73 CC genotype. This study is the first to investigate the MBL and MIF gene polymorphisms in Turkish children with CMP. We conclude that CC genotype of MIF (-173) polymorphism may be a risk factor for CMP patients. However, further studies with larger samples are needed to address the exact role of this polymorphism in CMP.
\end{abstract}

Key words: Cardiomyopathy, Children, Macrophage migration inhibitory factor, Mannose binding lectin, polymorphism.

\section{Introduction}

Cardiomyopathy (CMP) is defined as "diseases of the myocardium associated with cardiac disfunction" by World Health Organization (WHO), and it is an important cause of chronic congestive cardiac failure in children. The reported incidence for cardiomyopathies is $1,13-1,24$ per 100,000 children $[1,2]$.
Although the pathogenesis of disease is not fully understood, disturbances of the cellular and humoral immune system are frequently observed in CMPs, and myocardial inflammation is one of the commonest mechanisms in cardiomyopathy [3].

Mannose binding lectin (MBL) and Macrophage 
migration inhibitory factor (MIF) play substantial roles in the pathogenesis of several inflammatory and autoimmune disorders [4, 5]. Mannose binding lectin is a key molecule in innate immunity with the capacity to bind to microorganisms and kill them by initiating the lectin pathway of complement activation [5]. Furthermore, MBL has a major role in the modulation of inflammation but the mechanisms responsible for MBL interactions with inflammatory pathways is remain unclear [6]. Several studies suggest that, there is a modulatory role of MBL in autoimmune disease such as rheumatoid arthritis and systemic lupus erythematosus [6-8]. Previous studies show that the absence of MBL may affect occurrence of cardiovascular complications and myocardial ischemia/reperfussion injury, and CMP in MBL null animal models (9-11). Mannose Binding Lectin deficiency has been reported by three single nucleotide polymorphisms (SNPs) in codon 52, 54 and 57 of exon 1 in the MBL2 gene [6]. These SNPs are frequently referred to as variants B, C, and $\mathrm{D}(\mathrm{B}, \mathrm{C}$, and $\mathrm{D}$, denoting the substitution of aspartic acid for glysine codon 54, the substitution of gutamic acid for glycine codon 57, and the substitution of cysteine for arginine codon 52, respectively). Each of these variant alleles affect the stability of the final protein product, resulting in decreased serum levels and a dysfunctional MBL variant with a lower molecular weight than the normal MBL $[6,12]$.

Macrophage migration inhibitory factor is a constitutive element of the host antimicrobial defences and stress response that promotes proinflammatory function of the innate and acquired immune system. Macrophage migration inhibitory factor plays a regulator role in the immune response system and promotes proinflammatory biological activities. MIF is constitutively expressed in variety types of tissue and cells, including innate immune cells such as monocytes and macrophages [4]. Recently, it has been shown that MIF gene expression is higher in the heart with impaired glucose tolerance with cardiac dysfunction in rats, and elevated levels of MIF were associated with cardiac dysfunction in diabetic patients [13]. Mutations of the human MIF gene would predispose affected hosts to altered to sensibility or severity of inflammatory diseases such as juvenile idiopathic rheumatoid arthritis, and glomerulonephritis $[4,14,15]$.

To our knowledge, no studies have investigated the possible roles of MBL2 and MIF gene polymorphisms in children with CMP. The aim of the present study is to investigate any possible association between polymorphisms of MBL2 and MIF genes and CMP in a group of Turkish children, and to investigate the association between the identified genotypes and their clinical features.

\section{Materials and Methods}

Patients and controls: Twenty unrelated Turkish children with CMP, followed up in the Paediatric Cardiology Clinic of the Gaziantep University, Medical Faculty, were compared with 30 age-and sex-matched healthy controls. Relatives of CMP patients did not included as healthy controls. The diagnosis of CMP were made by signs and symptoms (irritability, feeding difficulties, weakness, fatigue, dizziness, syncope, tachypnea, tachycardia, hepatomegaly, and evidence of fluid retension), chest $X$ ray (cardiomegaly, pulmonary venous congestion, pulmonary oedema), electrocardiography (hypertrophy of left ventricle with strain, low voltage complexes) and echocardiographic signs. Cardiomyopathies were classified according to their structural and functional abnormalities such as dilated, in the setting of reduced left ventricular systolic function; hypertrophic, in the presence of unexplained septal hypertrophy of the left ventricule; restrictive, when impaired diastolic filling with preserved systolic function and normal ventricular wall thickness [1].The study was approved by the Local Ethics Committee of the Faculty of Medicine, and informed consents were obtained from the parents of children. The medical records of all children with CMP were reviewed for information about age, sex, and to document clinical presentation including symptoms, family history, laboratory and echocardiographic findings.

Genotyping: All patients and controls were analyzed for codon $54 \mathrm{~A} / \mathrm{B}$ (gly54asp) variation in exon 1 of MBL2 gene and $-173 \mathrm{G} / \mathrm{C}$ polymorphism in MIF gene. Genomic DNA was extracted from peripheral blood samples using the salting out procedure [16].

Genotyping of MBL2 gene codon 54 A/B: Polymerase Chain reaction (PCR) was performed using a forward (5'-TAGGACAGAGGGCATGCTC-3') and a reverse (5'-CAGGCAGTTTCCTCTGGAAGG-3') primers in a $25 \mu \mathrm{l}$ volume containing $50 \mathrm{ng}$ DNA, $2 \mathrm{mM}$ dNTPs, $2 \mathrm{nmol}$ of each primer, $1.5 \mathrm{mM} \mathrm{MgCl}_{2}$ and $3 \mathrm{U}$ Taq polymerase. The product $349 \mathrm{bp}$ was digested with restriction enzyme BanI (Fermentas) identify codon 54 polymorphism, respectively. BanI digestion was performed at $50{ }^{\circ} \mathrm{C}$ for 60 minutes with $5 \mathrm{U}$ enzyme. After enzyme digestion, products were visualized by electrophoresis on 3\% agarose gel. The BanI restriction site is present on wild type allele $A$ and absent on variant allele B [17].

Genotyping of MIF gene $-\mathbf{1 7 3}$ G/C: PCR was performed using a forward (5'-ACTAAGAAAGACCCGAGGC-3') and reverse (5'-GGGGCACGTTGGTGTTTAC-3') primers. For 
MIF (-173), a 330 bp fragment was amplified, which was then digested with AluI restriction enzyme (Fermentas), overnight at $37{ }^{\circ} \mathrm{C}$. The products were then separated on $3 \%$ agarose gel. The PCR product contains two restriction site for allele $C$ and one of these sites is destroyed when the presence of allele $G$ [18].

Statistical Analysis: All statistical analyses were performed with the Statistical Package for the Social Science for Windows (version 18.0; SPSS Inc, Chicago, IL, U.S.A.).Results are given as mean $\pm S D$, while allele frequencies and the distribution of genotype are given as \%. Clinical features and MBL/MIF gene polymorphisms were compared using the chi-square and the Fisher's exact tests. Differences between groups were compared by Kruskal-Wallis variant analysis and the Mann-Whitney U-test. Statistical significance was considered at $\mathrm{p}<0.05$. Hardy-Weinberg equilibrium (HWE) was calculated using De-finetti program [19]. Differences in allele and genotype distributions were assessed using odds ratios (ORs) and 95\% confidence intervals. Sample size was estimated using a power calculation based on other studies [20]. The minimum sample size was determined as 44 person in each group at the $80 \%$ power level with an a error of $5 \%$.

\section{Results}

Clinical features: The age ranged from 3 months to 13 years (mean: $3.47 \pm 3.38$ years; median: 2.00-IR:3.00) in patients with CMP $(n=20,10$ females/10 males). According to the echocardiographic evaluation, $80 \%(n=16)$ of the patients had dilated cardiomyopathy, $15 \%(\mathrm{n}=3)$ hypertrophic cardiomyopathy and $5 \%(n=1)$ restrictive cardiomyopathy. All patients had clinical findings of CMP. Echocardiographic findings of CMP patients were shown in Table 1 .

\section{Genotype frequencies of MBL2 and MIF genes}

The distribution of $\mathrm{AA}, \mathrm{AB}$, and $\mathrm{BB}$ genotypes for MBL codon 54 were $65 \%$ (13), $25 \%$ (5) and $10 \%$ (2) in CMP compared with $76.7 \%$ (23), $23.3 \%$ (7) and $0 \%(0)$ in the controls. The allele frequency of A/B in MBL was $77.5 \%$ (31), and $22.5 \%$ (9) in CMP compared with $88.3 \%$ (53), and $11.7 \%$ (7) in the controls. No significant difference was found between genotypes and alleles of MBL2 gene in patients and controls $(\mathrm{p}>0.05)$.

The distribution of GG, GC, and CC genotypes for MIF (-173) were $50 \%, 30 \%$, and $20 \%$ in CMP compared with $56.7 \%, 43.3 \%$ and $0 \%$ in the controls (Table 2). CC genotype was significantly higher in patient group ( $p=0.0210$, Table 2$)$. The allele frequency of G/C in MIF was $65 \%$, and $35 \%$ in CMP compared with $78.3 \%$, and $21.7 \%$ in the controls. The observed genotype counts were not deviated significantly from those expected according to the Hardy-Weinberg Equilibrium for MBL and MIF gene polymorphisms $(\mathrm{p}>0.05)$.

\section{Genotype frequencies of MBL2 and MIF genes}

The distribution of $\mathrm{AA}, \mathrm{AB}$, and $\mathrm{BB}$ genotypes for MBL codon 54 were $65 \%$ (13), $25 \%$ (5) and $10 \%$ (2) in CMP compared with $76.7 \%$ (23), $23.3 \%$ (7) and $0 \%(0)$ in the controls. The allele frequency of A/B in MBL was $77.5 \%$ (31), and $22.5 \%$ (9) in CMP compared with $88.3 \%$ (53), and $11.7 \%$ (7) in the controls. No significant difference was found between genotypes and alleles of MBL2 gene in patients and controls $(\mathrm{p}>0.05)$.

The distribution of GG, GC, and CC genotypes for MIF (-173) were $50 \%, 30 \%$, and $20 \%$ in CMP compared with $56.7 \%, 43.3 \%$ and $0 \%$ in the controls (Table 2). CC genotype was significantly higher in patient group ( $\mathrm{p}=0.0210$, Table 2 ). The allele frequency of G/C in MIF was $65 \%$, and $35 \%$ in CMP compared with $78.3 \%$, and $21.7 \%$ in the controls. The observed genotype counts were not deviated significantly from those expected according to the Hardy-Weinberg Equilibrium for MBL and MIF gene polymorphisms ( $\mathrm{p}>0.05)$.

Association between the identified genotypes and patients clinical/laboratory characteristics: We investigated correlations of MBL/MIF genotypes with clinical and laboratory findings of patients such as duration of symptoms, ejection fraction (EF), fractional shortening (FS), left ventricle end diastolic diameter (LVEDD), left ventricle end systolic diameter (LVESD), left ventricle end diastolic volume (LVEDV), and left ventricle end systolic volume (LVESV). No relationship was found between MBL/MIF genotypes and these parameters (data not shown).

In children with dilated CMP $(n=16)$, serum uric acid levels were higher in patients with MBL AA genotype $(p=0.033$, Table 3$)$, while plasma sodium $(\mathrm{Na})$ levels were higher in patients with MIF CC genotype $(\mathrm{p}=0.042$, Table 4$)$. 
Table I. Echocardiographic signs of children with cardiomyopathy (CMP).

\begin{tabular}{|c|c|c|c|}
\hline & $\begin{array}{l}\text { Dilated CMP Mean } \pm \text { SD } \\
(\text { min-max })(n=16)\end{array}$ & $\begin{array}{l}\text { Hypertrophic CMP Mean } \pm \text { SD } \\
(\text { min-max })(n=3)\end{array}$ & $\begin{array}{l}\text { Restrictive } \\
\text { CMP }(n=1)\end{array}$ \\
\hline Ejection fraction $(\mathrm{EF})(\%)$ & $\begin{array}{l}33.75 \pm 11.13 \\
(19-58)\end{array}$ & $\begin{array}{l}77.00 \pm 3.60 \\
(74-81)\end{array}$ & 58.00 \\
\hline Fractional shortening (FS) (\%) & $\begin{array}{l}15.07 \pm 5.89 \\
(8-29)\end{array}$ & $\begin{array}{l}35.67 \pm 6.02 \\
(30-42)\end{array}$ & 29.00 \\
\hline Left ventricle end diastolic diameter (LVEDD) $(\mathrm{cm})$ & $\begin{array}{l}4.75 \pm 1.04 \\
(2.40-5.90)\end{array}$ & $\begin{array}{l}2.83 \pm 0.72 \\
(2.00-3.30)\end{array}$ & 2.40 \\
\hline Left ventricle end systolic diameter (LVESD) $(\mathrm{cm})$ & $\begin{array}{l}3.98 \pm 1.07 \\
(1.70-5.40)\end{array}$ & $\begin{array}{l}1.63 \pm 0.40 \\
(1.20-2.00)\end{array}$ & 1.70 \\
\hline Left ventricle end diastolic volume (LVEDV) (ml) & $\begin{array}{l}119.94 \pm 42.08 \\
(29.60-173.00)\end{array}$ & $\begin{array}{l}32.600 \pm 17.30 \\
(12.70-44.10)\end{array}$ & 45.00 \\
\hline Left ventricle end systolic volume (LVESV) (ml) & $\begin{array}{l}82.15 \pm 37.53 \\
(18.10-141.00)\end{array}$ & $\begin{array}{l}8.15 \pm 4.67 \\
(3.36-12.70)\end{array}$ & 22.00 \\
\hline
\end{tabular}

Table 2. Genotype and allele frequencies of Macrophage Migration Inhibitory Factor (MIF) gene - $173 \mathrm{G} / \mathrm{C}$ polymorphism in children with cardiomyopathy (CMP).

\begin{tabular}{lllll}
\hline MIF Genotype & Control n(\%) & CMP Patients n(\%) & Odds Ratio (95\%C.I.) & p \\
\hline GG & $17(56.7)$ & $10(50)$ & $0.823(0.266-2.541)$ & $0.4793^{a}$ \\
GC & $13(43.3)$ & $6(30)$ & $0.560(0.169-1.858)$ & $0.2578^{a}$ \\
CC & $0(0)$ & $4(20)$ & $16.636(0.842-328.60)$ & $0.0210^{a}$ \\
MIF Allele & & & $0.513(0.210-1.256)$ & 0.1072 \\
G & $47(78.3)$ & $26(65)$ & $1.947(0.796-4.761)$ & 0.1072 \\
C & $13(21.7)$ & $14(35)$ & & \\
HWE $(p)$ & 0.129 & 0.127 & & \\
\hline
\end{tabular}

aFisher exact test, HWE: Hardy-Weinberg Equilibrium.

Table 3. Association with serum uric acid levels and Mannose Binding Lectin (MBL2) gene codon 54 A/B polymorphism in children with dilated cardiomyopathy.

\begin{tabular}{llll}
\hline MBL genotypes & Serum uric acid level $(\mathrm{mg} / \mathrm{dL})$ Mean \pm SD (min-max) & $95 \%$ CI & $\mathrm{p}$ \\
\hline AA & $6,139 \pm 1,508(4,5-8,4)$ & $4,979-7,299$ & 0.033 \\
AB & $3,000 \pm 0,989(2,3-3.7)$ & $-5,894-11,894$ & \\
\hline
\end{tabular}

Table 4. Association with plasma sodium ( $\mathrm{Na}$ ) levels and Macrophage Migration Inhibitory Factor (MIF) gene - I73 G/C polymorphism in children with dilated cardiomyopathy.

\begin{tabular}{llll}
\hline MIF genotypes & Plasma Na level $(\mathrm{mEq} / \mathrm{L})$ Mean \pm SD (min-max) & $95 \%$ CI & $\mathrm{p}$ \\
\hline CC & $137,50 \pm 2,121(136-139)$ & $118,44-156,56$ & 0.042 \\
GC & $131,00 \pm 1,414(130-132)$ & $118,29-143,71$ & \\
\hline
\end{tabular}




\section{Discussion}

Although the pathogenesis of CMP is not fully understood, cellular as well as humoral autoimmun responses are critically associated with the pathogenesis and progression of the disease. Furthermore, disturbances of the cellular and humoral immune system are frequently observed, and myocardial inflammation is one of the commonest mechanisms in cardiomyopathy [3]. Two of the postulated factors are; firstly, myocardial inflammation mediated by the effector cells of the immune system; and secondly locoregional effect of inflammatory mediators, released by the infiltrating lymphocytes, macrophages or endothelial cells [21]. Both MIF and MBL play several roles in innate and adaptive immune responses, and changes in levels of MBL and MIF are implicated as playing causative role in many disease states $[4,6,22]$.

Better understanding of the molecular genetics underlying CMP may provide a means of early diagnosis, genotype-based therapy, and even prevention of the disease.

Mannose binding lectin deficiency is associated with susceptibility to infectious and autoimmun diseases and serum MBL levels vary substantially because of the variant alleles in exon 1 of the MBL2 gene, located on chromosome 10 in the humans [22]. In the present study, homozygosity for MBL variant allele was observed only two patients with dilated CMP and the A/A genotype was higher than the variant alleles in CMP patients, but these results were not statistically significant.

Messias-Reason et al, suggested that wild type variants of MBL2 gene was significantly higher in rheumatic hearth diseases [23]. Ramasawmy et al. reported that subjects homozygous for the wild type allele had a higher concentration of MBL than heterozygous subjects and than homozygous for the variant MBL2 alleles [24]. Schafranski et al showed that, genotypes associated with a higher level of MBL seem to represent a risk factor for the evolution of rheumatic carditis, and MBL play a substantial role in the progression of the disease to chronic form [25]. However, some studies indicated that there was either no association of MBL gene polymorphisms and systemic lupus erythematosus (SLE) and rheumatoid arthritis (RA), or even an increased risk for RA has been demonstrated in MBL insufficiency $[8,26]$. In the present study, homozygosity for MBL variant allele was observed only two patients with dilated CMP and the A/A genotype was higher than the variant alleles in CMP patients, but these results were not statistically significant. These different results in literature highlight the need for further detailed studies to understand the exact role of MBL2 gene polymorphism in several diseases.

We investigated correlations of MBL genotypes with clinical and laboratory findings of the disease, and found that uric acid levels were higher in patients with MBL AA genotype than the other genotypes. Uric acid is a useful marker for the decompensation trigger in chronic heart failure, and might be related to inflammatory responses [27]. It has been shown that the left ventricular hypertrophy has an important potential to increase uric acid level [28]. Gullu et al. measured uric acid levels in idiopathic dilated cardiomyopthy, and they observed that serum uric acid levels are significantly higher in the lower coronary flow reverse group than in the higher coronary flow reverse group [29]. Interestingly, Garred et al reported that homozygous for wild type alleles in exon 1 of MBL2 gene were more likely to show evidence of persistent inflammation [30]. We suggest that the reason of increased uric acid level in our patients may be both inflammation and chronic heart failure.

Macrophage migration inhibitory factor plays an important role in the control of innate immun responses and promotes proinflammatory biological activities. Four polymorphisms of the human MIF gene $(-794,-173,+254,+656)$ have been reported, and this polymorphisms would predispose affected hosts to altered susceptibility to or severity of inflammatory or infectious disease [4]. Patients with $-173 \mathrm{C}$ allele (that is, guanine-to-cytosine transition at position -173) had increased levels of MIF, and increased MIF concentrations had been associated with severe clinical manifestations, high severity scores, and poor outcome of inflammatory disease [4, 31, 32]. In the other studies, no association were found in genotype distributions of MIF -173 G/C polymorphism between ulcerative colitis, juvenile rheumatoid arthritis and healthy controls [14, 33]. However, Donn et al showed that MIF -173 C allele was associated with juvenile idiopathic arthritis [31, 32]. Moreover, MIF-173 C allele had a significantly greater number of joints with active arthritis and was associated with a poor response to glucocorticoids in patients with juvenile idiopathic arthritis [31]. Berdeli et al showed that, the MIF -173 C allele was a poor outcome predictor in JRA [14].

Miller et al. demonstrated that MIF released from ischemic cardiomyocytes stimulates adenosine monophosphate-activated protein kinase (AMPK) activation and promotes glucose uptake, and thereby protects the hearth against ischaemia reperfusion injury [34]. Jian et al found that MIF protein is constitutively expressed by cardiomyocytes in vivo and is increased in the myocardium of infants with cyanotic 
cardiac defects in myocardial biopsy materials [35]. Tereshchenko et al did not reveal an association of the myocardial infarction with the MIF-173 C allele polymorphism [36]. In the present study, homozygosity for MIF-173 C allele was observed only four patients with dilated CMP. Recently, it has been shown that presence of $-173 \mathrm{C}$ allele indicates higher MIF levels [37], and cardiac inflammation (autoimmune, viral or post viral) has an important component in the pathogenesis of dilated CMP [38]. Therefore we suggest that, CC genotype in our patients may be partially responsible from inflammation in dilated CMP, and MIF polymorphism may contribute to MIF release from cardiomyocytes in children with CMP. However, we could not find any relationship between MIF genotypes and cardiac functions. Considering the limited number of our patients, we cannot say that MIF polymorphism does not modulate cardiac functions. Further detailed studies with large patient numbers are needed for this suggestion.

It has been shown that, plasma brain natriuretic peptide (BNP) concentrations were increased in various forms of heart disease with impaired left ventricular systolic function including cardiomyopathy [39]. Natriuretic peptides inhibit the transport of sodium and water in proximal tubules and block reabsorption of sodium [40]. In this study, plasma sodium levels were higher in patients with MIF CC genotype than the other genotypes. However, we could not conclude whether CC genotype of MIF has any effect on BNP with this study. This hypothesis needs further evaluation.

\section{Conclusion}

This study is the first to investigate the MBL and MIF gene polymorphisms in Turkish children with CMP. We conclude that CC genotype of MIF (-173) gene may be a risk factor for CMP patients. However, further studies with larger samples are needed to address the exact role of this polymorphism in CMP.

\section{Competing Interests}

The authors have declared that no competing interest exists.

\section{References}

1. Nugent AW, Daubeney DE, Chandras P, et al. National Australian Childhood Cardiomiyopathy Study. The epidemiology of childhood cardiomiyopathy in Australia. N Engl J Med. 2003; 348: 1639-46.

2. Lipshultz SE, Sleeper TA, Towbin JA, et al. The incidence of pediatric cardiomiyopathy in two regions of the United States. N Engl J Med. 2003; 348: 1647-55

3. Maisch B, Richter A, Sandmoller A, BMBF - Herth Failure Network. Inflammatory dilated cardiomyopathy (DCMI). Herz 2005; 30: 535-44.

4. Renner P, Roger T, Calandra T. Macrophage migration inhibitory factor: Gene polymorphisms and suspectibility to inflammatory diseases. Clin Infect Dis. 2005; 41: 513-9.
5. Ruskamp JM, Hoekstra MO, Rovers MM, et al. Mannose-binding lectin and upper respiratory tract infections in children and adolescents. Arch Otolaryngol Head Neck Surg. 2006;132: 482-6.

6. Turner MW. The role of mannose-binding lectin in health and disease. Mol Immunol. 2003; 40: 423-9.

7. Garred P, Madsen HO, Halberg P, et al. Mannose-binding lectin polymorphisms and susceptibility to infection in systemic lupus erythematosus. Arthritis Rheum 1999; 42: 2145-52.

8. Ip WK, Lau L, Chan SY, et al. Mannose-binding lectin and rheumatoid arthritis in Southern Chinese. Arthritis Rheum. 2000; 43: 1679-87.

9. Zou C, La Bonte LR, Pavlov VI, et al. Murine hyperglycemic vasculopathy and cardiomyopathy: whole-genome gene expression analysis predicts cellular targets and regulatory networks influenced by mannose binding lectin. Front Immunol. 2012; 3:15.

10. Pavlov VI, La Bonte LR, Baldwin WM, et al. Absence of mannose-binding lectin prevents hyperglycemic cardiovascular complications. Am J Pathol. 2012; 180:104-12.

11. Busche MN, Walsh MC, McMullen ME, et al. Mannose-binding lectin plays a critical role in myocardial ischaemia and reperfusion injury in a mouse model of diabetes. Diabetologia. 2008; 51: 1544-51.

12. Schafranski MD, Ferrari LP, Scherner D, et al. High-producing MBL2 genotypes increase the risk of acute and chronic carditis in patients with history of rheumatic fever. Mol Immunol. 2008; 45: 3827-31.

13. Yu XY, Chen HM, Liang JL, et al. Hyperglycemic myocardial damage is mediated by proinflammatory cytokine: macrophage migration inhibitory factor. PLoS One. 2011; 25:e16239.

14. Berdeli A, Ozyürek AY, Ulger Z, et al. Association of macrophage migration inhibitory factor gene $-173 \mathrm{G} / \mathrm{C}$ polymorphism with prognosis in Turkish children with juvenile rheumatoid arthritis. Rheumatol Int. 2006; 26: 726-31.

15. Lan HY, Yang N, Nikolic- Paterson DJ, et al. Expression of macrophage migration inhibitory factor in human glomerulonephritis. Kidney Int. 2000; 57: 499-509.

16. Miller SA, Dykes DD, Polesky HF. A simple salting out procedure for extracting DNA from human nucleated cells. Nucleic Acids Res. 1988; 16: 1215.

17. Vardar F, Pehlivan S, Onay H, et al. Association between mannose binding lectin polymorphisms and predisposition to bacterial meningitis. Turk J Pediatr. 2007; 49: 270-3.

18. Akcali A, Pehlivan S, Pehlivan M, et al. Association of macrophage migration inhibitory factor gene promoter polymorphisms with multiple sclerosis in Turkish patients. J Int Med Res. 2010; 38: 69-77.

19. [Internet] Strom TM, Wienker TF. Hardy-Weinberg equilibrium online analysis program. http:/ihg.gsf.de/cgi-bin/hw/hwa2.pl

20. Col-Araz N, Pehlivan S, Baspinar O, et al. Association of macrophage migration inhibitory factor and mannose-binding lectin-2 gene polymorphisms in acute rheumatic fever. Cardiol Young. 2012; [Epub ahead of print].

21. Pankuweit $S$, Ruppert V, Maisch B. Inflammation in dilated cardiomyopathy. Herz 2004; 29: 788-93.

22. Worthley DL, Bardy PG, Mullighan CG. Mannose-binding lectin: biology and clinical implications. Intern Med J. 2005; 35: 548-55.

23. Messias Reason LJ, Schafranski MD, Jensenius JC, et al. The association between mannose-binding lectin gene poymorphism and rheumatic hearth disease. Hum Immunol. 2006; 67: 991-8.

24. Ramasawmy R, Spina SG, Fae KC, et al. Association of mannose-binding lectin gene polymorphism but not of mannose-binding serine protease 2 with chronic severe aortic regurgitation of rheumatic etiology. Clin Vaccine Immunol. 2008; 15: 932-6.

25. Schafranski MD, Ferrari LP, Scherner D, et al. High-producing MBL2 genotypes increase the risk of acute and chronic carditis in patients with history of rheumatic fever. Mol Immunol. 2008; 45: 3827-31.

26. Horiuchi $\mathrm{T}$, Tsukamoto $\mathrm{H}$, Morita $\mathrm{C}$, et al. Mannose-binding lectin (MBL) gene mutation is not a risk factor for systemic lupus erythematosus (SLE) and rheumatoid arthritis (RA) in Japanese. Genes Immun. 2000; 1: 464-6.

27. Leyva F, Anker SD, Godsland IF, et al. Uric acid in chronic heart failure: A marker of chronic inflammation. Eur Hearth J. 1998; 19: 1814-22.

28. Kurata A, Shigematsu Y, Higaki J. Sex-related differences in relations of uric acid to left ventricular hypertrophy and remodeling in Japanese hypertensive patients. Hypertens Res. 2005; 28: 133-9.

29. Gullu H, Erdogan D, Caliskan M, et al. Elevated serum uric acid levels impair coronary microvascular function in patients with idiopathic cardiomiyopathy. Eur J Hearth Fail. 2007; 9: 466-8.

30. Garred P, Madsen HO, Marquarth $\mathrm{H}$, et al. Two edged role of mannose binding lectin in rheumatoid arthritis: a cross sectional study. J Rheumatol. 2000; 27: 26-34. 
31. De Benedetti FD, Meazza C, Vivarelli M, et al. The British Paediatric Rheumatology Study Group. Functional and prognostic relevance of the -173 polymorphism of the macrophage migration inhibitory factor gene in systemic-onset juvenile idiopathic arthritis. Arthritis Rheum. 2003; 48: 1398-407.

32. Donn R, Alourfi Z, De Benedetti F, et al. The British Paediatric Rheumatology Study Group. Mutation screening of the macrophage migration inhibitory factor gene. Positive association of a functional polymorphism of macrophage migration inhibitory factor with juvenile idiopathic arthritis. Arthritis Rheum. 2002; 46: 2402-9

33. Nohara H, Okayama $\mathrm{N}$, Inoune $\mathrm{N}$, et al. Association of the $173 \mathrm{G} / \mathrm{C}$ polymorphism of the macrophage migration inhibitory factor gene with ulserative colitis. J Gastroenterol. 2004; 39: 242-6.

34. Miller EJ, Li J, Leng L, et al. Macrophage migration inhibitory factor stimulates AMP-activated protein kinase in the ischaemic hearth. Nature 2008; 451: 578-82

35. Jian $\mathrm{Z}, \mathrm{Li} \mathrm{JB}, \mathrm{Ma} \mathrm{RY}$, et al. Increase of macrophage migration inhibitory factor (MIF) expression in cardiomyocytes during chronic hypoxia. Clin Chim Acta. 2009; 405:132-8.

36. Tereshcenko IP, Petrkova J, Mrazek F, et al. The macrophage migration inhibitory factor (MIF) gene polymorphism in Czech and Russian patients with myocardial infarction. Clin Chim Acta. 2009; 402: 199-202.

37. Xie Q, Wang SC, Bian G, et al. Association of MIF -173G/C and MBL2 codon 54 gene polymorphisms with rheumatoid arthritis: a meta-analysis. Hum Immunol. 2012; [Epub ahead of print]

38. Pankuweit S, Ruppert V, Maisch B. Inflammation in dilated cardiomyopathy. Herz 2004; 29: 788-93.

39. Bielecka-Dabrowa A, Wierzbicka M, Dabrowa M, et al. New methods in laboratory diagnostics of dilated cardiomiyopathy. Cardiol J. 2008; 15: 388-95.

40. Bettencourt PM. Clinical usefulness of B-type natriuretic peptide measurement: present and future perspectives. Hearth 2005; 91: 1489-94. 